Pesq. Vet. Bras. 29(7):498-508, julho 2009

\title{
Morte súbita em bovinos causada pela ingestão de Pseudocalymma elegans (Bignoniaceae) no município de Rio Bonito, RJ'
}

\author{
Michel A. Helayel ${ }^{2}$, Ticiana N. França ${ }^{3}$, Josilene N. Seixas ${ }^{4}$, Vivian A. \\ Nogueira ${ }^{4}$, Saulo A. Caldas ${ }^{4}$ e Paulo Vargas Peixoto ${ }^{5}$
}

\begin{abstract}
Helayel M.A., França T.N., Seixas J.N., Nogueira V.A., Caldas S.A. \& Peixoto P.V. 2009. [Sudden death in cattle caused by ingestion of Pseudocalymma elegans (Bignoniaceae) in the county of Rio Bonito, Rio de Janeiro.] Morte súbita em bovinos causada pela ingestão de Pseudocalymma elegans (Bignoniaceae) no município de Rio Bonito, RJ. Pesquisa Veterinária Brasileira 29(7):498-508. Curso de Pós-Graduação em Medicina Veterinária, Instituto de Veterinária, Universidade Federal Rural do Rio de Janeiro, Seropédica, RJ 23890-000, Brazil. E-mail: michel abdallavet@yahoo.com.br

Natural poisoning by Pseudocalymma elegans, a plant that causes "sudden death" and only occurs in the State of Rio de Janeiro, is described in a cow. This condition was experimentally reproduced in three calves and three rabbits with the plant collected in the area where the deaths had occurred. Postmortem and histopathological examinations of the natural case in the cow did not reveal significant alterations. Oral administration of $1 \mathrm{~g} /$ $\mathrm{kg}$ of the sprouts of $P$. elegans caused death of the calf 5 hours and 30 minutes after beginning of the administration. The dose of $0.5 \mathrm{~g} / \mathrm{kg}$ caused death of another calf with onset of symptoms after 3 hours and 24 minutes and a course of 73 hours and 12 minutes. Animals that ingest borderline doses may show a longer course with a characteristic clinical picture of heart impairment. The dose of $0.25 \mathrm{~g} / \mathrm{kg}$ did not cause death, but only clinical signs. Heart palpitation and arrhythmia, increase of breathing frequency, reluctance in moving, positive venous pulse, ingurgitated jugular veins, falling down and peddling movements shortly before death, were observed. At postmortem examination the lesions were those of acute heart insufficiency, and histopathological examination revealed the typical kidney lesion (hydropic-vacular degeneration in the distal convoluted tubules) seen in poisoning by plants that cause "sudden death". In the experimentally poisoned rabbits the clinical course was less than 1-2 minutes. In the kidney of two rabbits there was also the characteristic microscopic lesion. The presence of the plant in the county of Rio Bonito had not been known by the veterinarians. It is concluded that the plant could be more toxic than described before.
\end{abstract}

INDEX TERMS: Poisonous plants, Pseudocalymma elegans, Bignoniaceae, plant poisoning, sudden death, cattle, rabbits.

\footnotetext{
${ }^{1}$ Recebido em 15 de janeiro de 2009.

Aceito para publicação em 21 de fevereiro de 2009.

Parte da Dissertação de Mestrado do primeiro autor.

2 Mestrando do Curso de Medicina Veterinária, Universidade Federal Rural do Rio de Janeiro (UFRRJ), Seropédica, RJ 23890-000,

Brasil..Autor para correspondência: michel_abdallavet@yahoo.com.br

${ }^{3}$ Departamento d e Epidemiologia e Saúde Pública, Instituto de Veterinária, UFRRJ, Seropédica, RJ.

${ }^{4}$ Doutorante do Curso de Ciências Veterinárias, Instituto de Veterinária, UFRRJ, Seropédica, RJ.

${ }^{5}$ Depto Nutrição Animal e Pastagem, IZ, UFRRJ, Seropédica, RJ.
}

RESUMO.- Descreve-se a intoxicação natural por Pseudocalymma elegans em pelo menos um bovino em Rio Bonito, RJ e a reprodução experimental dessa intoxicação em três bovinos e em 3 coelhos com exemplares dessa planta colhida no local onde ocorreu a morte. Necropsia e histopatologia do bovino naturalmente intoxicado não revelaram alterações significativas. A administração, por via oral, de $1 \mathrm{~g} / \mathrm{kg}$ da brotação da planta causou a morte do bovino dentro de $5 \mathrm{~h}$ e 30 minutos após o início da administração, já pela administração de $0,5 \mathrm{~g} / \mathrm{kg}$, a morte do 
animal ocorreu após 76 horas e 36 minutos. A dose de $0,25 \mathrm{~g} / \mathrm{kg}$ foi capaz de causar sintomas, mas não levou a morte. A sintomatologia caracterizou-se por arritmia cardíaca, taquicardia, aumento da freqüência respiratória, relutância em se mover, pulso venoso positivo, jugulares e grandes vasos ingurgitados, queda ao solo e movimentos de pedalagem, seguindo-se o óbito. À necropsia foram verificadas alterações compatíveis com às observadas na insuficiência cardíaca aguda, e o exame histopatológico revelou a lesão renal típica (degeneração hidrópica em túbulos contornados distais) de intoxicação por plantas que causam "morte súbita". Nos coelhos, a evolução variou entre menos de um minuto a dois minutos. $O$ exame histopatológico do rim de dois coelhos também revelou a lesão microscópica característica. Essa planta ainda não havia sido mapeada nessa área do Estado do Rio de Janeiro. Conclui-se que a planta pode ser mais tóxica do que anteriormente descrito.

TERMOS DE INDEXAÇÃO: Plantas tóxicas, Pseudocalymma elegans, Bignoniaceae, intoxicação por planta, morte súbita, bovinos, coelhos.

\section{INTRODUÇÃO}

No Brasil, as plantas que causam "morte súbita" são as mais importantes, pelo menos no que diz respeito aos prejuízos econômicos. Das cerca de 100 plantas tóxicas de interesse pecuário conhecidas no país, 12 pertencem a este grupo e são responsáveis por metade das mortes causadas por plantas tóxicas em bovinos no país. A principal planta desse grupo é Palicourea marcgravii, responsável pela grande maioria das mortes de bovinos intoxicados por plantas no território nacional. Outras plantas do gênero, capazes de causar "morte súbita", têm distribuição geográfica mais limitada. Em geral, os animais que ingerem essas plantas, morrem sem sinais clínicos prévios, ou com sintomas que passam despercebidos; à necropsia não se encontra lesões significativas. Pelo exame histológico, porém, em muitos animais intoxicados encontra-se, no rim, lesão considerada característica no epitélio dos túbulos contornados distais. (Tokarnia et al. 2000)

Pseudocalymma elegans, um cipó da família Bignoniaceae, sem nome popular, foi a primeira planta tóxica estudada no Estado do Rio de Janeiro e uma das primeiras estudadas no Brasil. Em 1941, Mello \& Fernandes esclareceram que as mortandades de bovinos que ocorriam no Vale do Rio Sant'Ana, município de Vassouras (atualmente Miguel Pereira), RJ, eram provocadas pela ingestão de $P$. elegans. Atualmente sabe-se que essa planta ocorre também nos municípios de Paracambi, Rio de Janeiro (Campo Grande) e Saquarema, RJ, onde tem como habitat principal a encosta de morros (Tokarnia et al. 2000). Embora o princípio tóxico dessa planta seja desconhecido, presume-se que haja uma interferência sobre o funcionamento cardíaco, de forma que os animais morreriam de insuficiência cardíaca aguda (Consorte et al. 1994). Sob condições naturais, a intoxicação por $P$. elegans só tem sido observada em bovinos (Mello \&
Fernandes 1941, Tokarnia 2004), embora haja suspeitas de ocorrência de casos de intoxicação natural em eqüinos (Tokarnia et al. 1995). Experimentalmente têm sido intoxicados, por via oral, além de bovinos (Mello \& Fernandes 1941, Tokarnia et al. 1969), também caprinos (Mello \& Fernandes 1941, Tokarnia et al. 1993), ovinos (Consorte et al. 1994), eqüinos (Tokarnia et al. 1995), coelhos e cobaias (Mello \& Fernandes 1941, Tavares et al. 1974).

Em uma propriedade no município de Rio Bonito, no interior do Estado do Rio de Janeiro, nos meses de agosto de 2005 e maio de 2006 ocorreram casos de "morte súbita", com histórico de que, quando bovinos eram postos no morro da propriedade, dias depois ocorriam mortes com evolução superaguda, sem sinais clínicos prévios. A pastagem estava significativamente invadida por $P$. elegans (Fig.1).

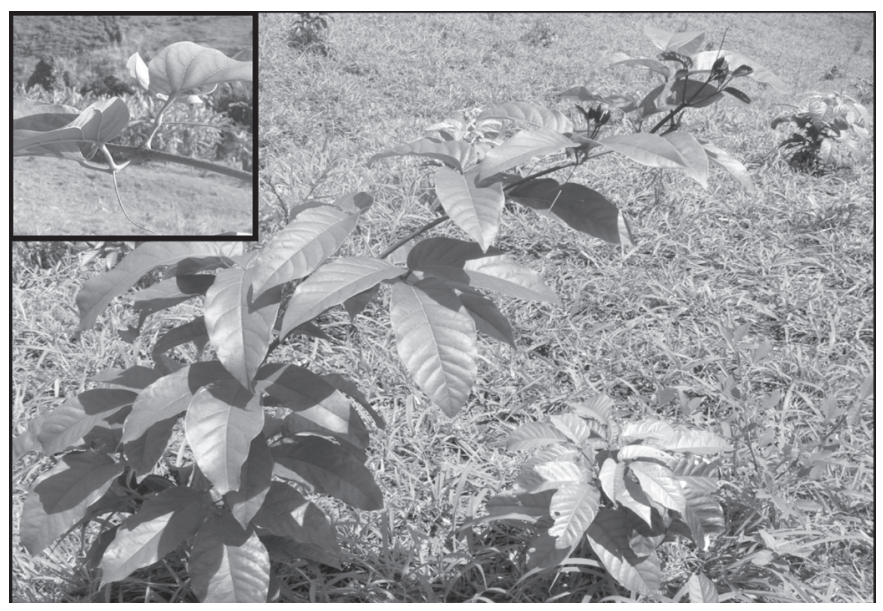

Fig.1. Morte súbita em bovinos causada pela ingestão de Pseudocalymma elegans (Bignoniaceae) no município de Rio Bonito, Rio de Janeiro. Pastagem onde ocorreu o surto. $P$. elegans, note as folhas novas de coloração roxa e a brotação ao lado da planta adulta. No detalhe: dois folíolos e uma gavinha são característicos.

O presente trabalho teve como objetivo descrever os aspectos epidemiológicos e clínico-patológicos da ocorrência de pelo menos um caso de intoxicação natural por $P$. elegans em Rio Bonito, Estado do Rio de Janeiro, e confirmar, através de experimentos em bovinos e coeIhos, que a planta encontrada nessa área é tóxica e responsável pelos casos naturais.

\section{Intoxicação natural}

\section{MATERIAL E MÉTODOS}

Animal. Bovino, fêmea, SRD, pesando cerca de $250 \mathrm{~kg}$. Os animais que morreram anteriormente a este não foram necropsiados.

Local. A colheita do histórico, o exame clínico e a necropsia do bovino intoxicado naturalmente foram realizados na propriedade onde ocorreu a mortandade, em Rio Bonito, Rio de Janeiro. O material coletado para estudo histológico foi processado no Setor de Anatomia Patológica, Projeto Sanidade Animal Embrapa/UFRRJ. 


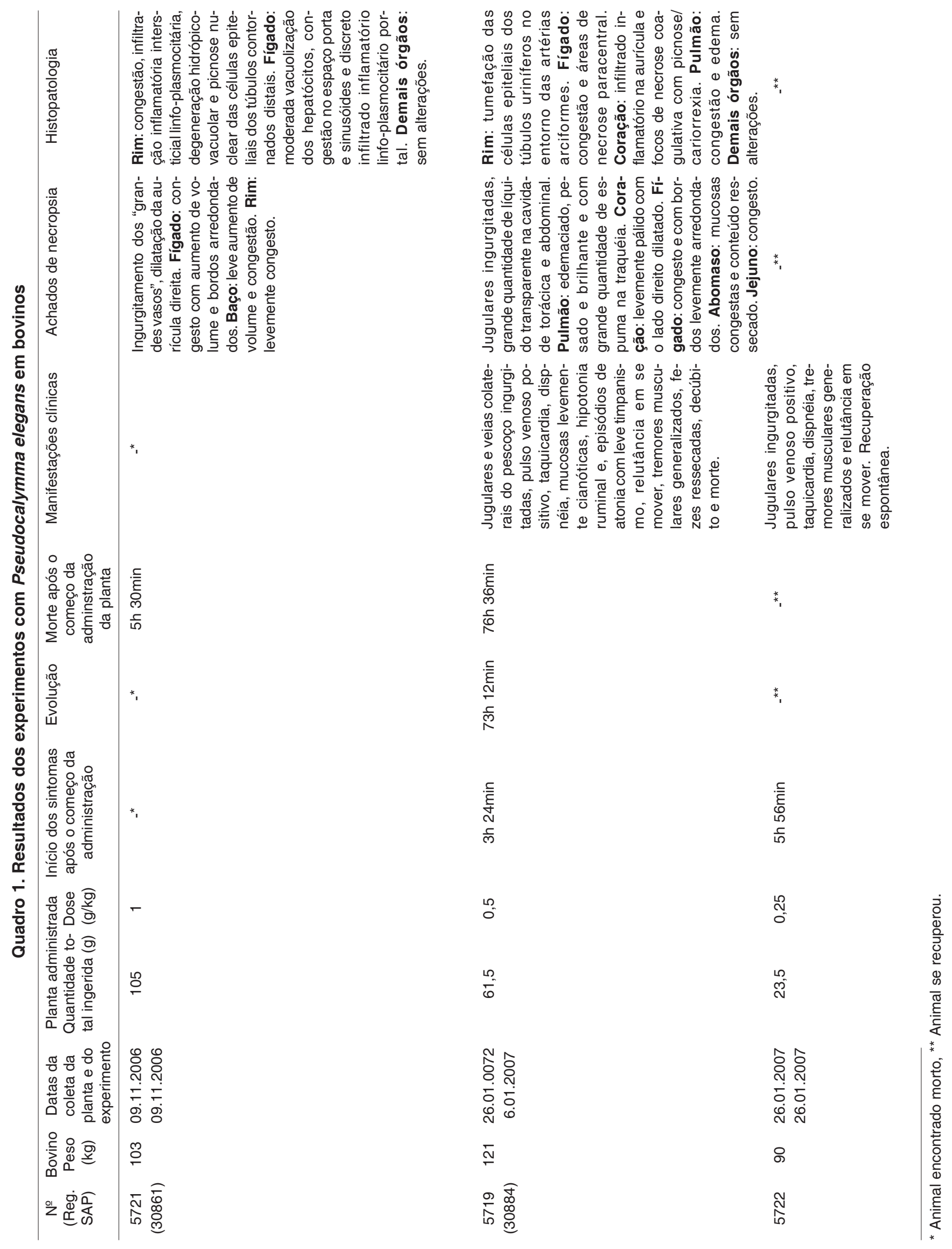




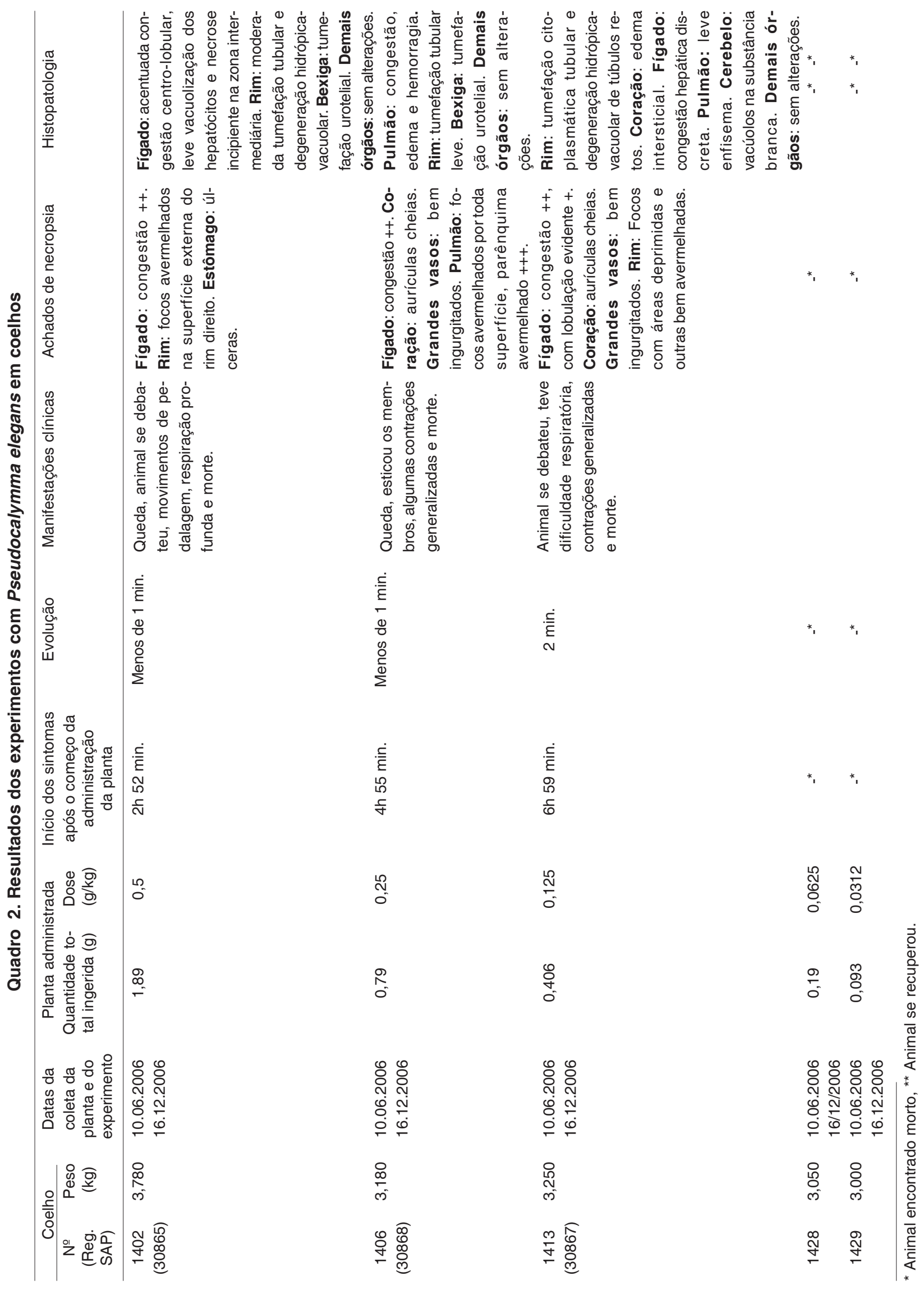


Necropsia. A necropsia foi realizada aproximadamente duas horas após a morte do animal e fragmentos de fígado, baço, rim, coração, pulmão, músculo esquelético e sistema nervoso central (SNC) foram coletados, fixados em formol a $10 \%$ e enviados para análise histopatológica no Setor de Anatomia Patológica, Projeto Sanidade Animal.

\section{Intoxicação experimental}

Animais. Na experimentação com Pseudocalymma elegans, a planta tóxica suspeita de ter causada a mortandade, foram utilizados três bovinos mestiços, de ambos os sexos, com 90, 103 e 121 kg, livres de doenças, endoparasitos e ectoparasitos, que receberam, respectivamente, doses de $1 \mathrm{~g} / \mathrm{kg}, 0,5 \mathrm{~g} / \mathrm{kg}$ e $0,25 \mathrm{~g} / \mathrm{kg}$ do broto da planta fresca procedente da propriedade onde ocorreu o caso de intoxicação natural (Quadro 1), e 5 coelhos, de ambos os sexos, com peso de3.180-3.780g, que receberam 0,5g/kg, 0,25g/kg, 0,125g/kg, 0,0625g/kg e 0,0312g/ $\mathrm{kg}$ da planta dessecada e moída, também procedente do local onde ocorreu a intoxicação natural (Quadro 2).

Local. Os experimentos foram desenvolvidos no Setor de Anatomia Patológica, Projeto Sanidade Animal Embrapa/ UFRRJ. Os bovinos foram mantidos em baias, medindo $2 \times 2 \mathrm{~m}$, com água e capim (Panicum maximum) à vontade. Os coelhos, durante o estudo, permaneceram em gaiolas pré-fabricadas de ferro galvanizado, com comedouro e bebedouro.

Procedimenos experimentais em bovinos. Antes da administração da planta, os animais foram examinados, com avaliação da temperatura retal, da freqüência cardíaca e respiratória, dos movimentos ruminais e das mucosas visíveis. O exame foi repetido a cada hora até a morte ou recuperação do animal. As folhas frescas da brotação de $P$. elegans, foram administradas manualmente, por via oral. As necropsias foram feitas logo após a morte dos animais. Todos os órgãos foram avaliados e fragmentos de fígado, rim, baço, pâncreas, adrenal, coração, pulmão, intestino, músculo e do sistema nervoso central foram coletados e fixados em formol a $20 \%$. Após a fixação em formalina, os fragmentos de órgãos foram desidratados em álcool absoluto, tratados com xilol, embebidos e incluídos em parafina, cortados de 5 micrômetros e corados pela Hematoxilina \& Eosina (HE).

Procedimentos experimentais em coelhos. Doses de $0,5 \mathrm{~g} /$ $\mathrm{kg}, 0,25 \mathrm{~g} / \mathrm{kg}, 0,125 \mathrm{~g} / \mathrm{kg}, 0,0625 \mathrm{~g} / \mathrm{kg}$ e $0,0312 \mathrm{~g} / \mathrm{kg}$ de $P$. elegans dessecada foram administradas por sonda intragástrica a 5 coelhos respectivamente. A planta foi coletada em 10.06.2006 e seca à sombra durante três dias, triturada em moinho Wiley com malha 60 e conservada em vidros fechados com tampa plástica e guardados à temperatura ambiente. A administração foi feita sob forma de suspensão aquosa por via intragástrica, através de sonda (orogástrica) de plástico transparente de $0,5 \mathrm{~cm}$ de diâmetro interno, adaptada a um funil de separação, conforme técnica descrita anteriormente por Döbereiner et al. (1976). A necropsia foi realizada logo após a morte do animal. Fragmentos de fígado, rim, baço, pâncreas, adrenal, estômago, útero, ovário, coração, pulmão, músculo e SNC foram coletados, fixados em formol a $20 \%$, processados rotineiramente para histopatologia e corados pela hematoxilina-eosina (HE).

\section{RESULTADOS}

\section{Intoxicação natural}

Aspectos epidemiológicos e clínicos. Em uma propriedade, de aproximadamente 10 hectares, localizada no município de Rio Bonito (RJ), vieram a morte 13 bovinos, de ambos os sexos, sem raça definida, entre a segunda metade de maio e o fim de setembro de 2005. O rebanho era constituído por 35 bovinos mestiços, de 12-36 meses de idade; alguns animais foram adquiridos em março do mesmo ano. Os bovinos eram criados em regime de pastejo extensivo, não recebiam suplementação alimentar, porém tinham acesso a sal mineral comercial. Todos os animais haviam sido vacinados contra raiva, febre aftosa e clostridiose. Durante a primeira visita, realizada em 15 de agosto de 2005, o proprietário relatou que fazia uso de dois pastos, um na parte da "baixada" e outro na parte mais alta (morro). Quinze a 30 dias depois o rebanho ser introduzido no pasto mais alto, parte dos animais apresentaram relutância em caminhar, marcha desequilibrada, queda, dificuldade para levantar, decúbito lateral, movimentos de pedalagem, tremores musculares, respiração ofegante, mugidos e, logo em seguida, morte; alguns animais apresentavam fezes recobertas com muco. O proprietário relatou, ainda, que alguns animais foram encontrados mortos, sem apresentar sintomas prévios. Durante essa visita, dois animais apresentaram sintomatologia e um deles foi examinado. Além dos sinais acima relatados, constatou-se taquicardia e pupilas não-responsivas à luz. Esses dois últimos animais se recuperaram. Durante a vistoria das pastagens, observou-se, de início, apenas grande quantidade de Cestrum laevigatum (Solanaceae) tanto no pasto do morro quanto no pasto da baixada. Foi solicitado ao proprietário que fizesse o controle de plantas invasoras no pasto, com a utilização de enxada e herbicida. Ele optou por fazer o uso de queimadas em todo pasto do morro. Com isso as mortes cessaram, por um tempo. A segunda visita ocorreu em 24 de maio de 2006, pois o proprietário realizou novo contato, para que fizéssemos a necropsia de uma novilha, mestiça, de aproximadamente $250 \mathrm{~kg}$. O mesmo informou que, pela manhã deste dia, havia observado esse animal e o resto do rebanho, e não havia notado nenhuma alteração. Às 8:00 horas, o proprietário transferiu os animais do pasto do morro para a baixada e, após 20 minutos, encontrou a novilha morta. Iniciamos a necropsia do animal às 9 horas da manhã. Após a necropsia foi feita inspeção nos pastos da propriedade que estava significativamente invadida por $P$. elegans. Em uma terceira visita, em 21 de novembro de 2006, observou-se que a planta brotava em grande quantidade a partir dos troncos.

Necropsia. $\mathrm{O}$ animal encontrava-se em decúbito lateral direito, apresentava bom escore corporal e mucosas normocoradas. Não foram observados ectoparasitos, lesão cutânea ou alterações dignas de nota ao exame dos órgãos.

Histopatologia. O rim apresentava leve infiltração inflamatória linfo-plasmocitária intersticial, multifocal, localizada, sobretudo junto a glomérulos. O fígado e baço não apresentavam lesões significativas. Havia leve enfisema pulmonar.

\section{Reprodução experimental em bovinos \\ Influência do exercício. O Bovino 5721 que recebeu $1 \mathrm{~g} / \mathrm{kg}$, não foi exercitado. Embora tenham começado a}


apresentar os sintomas antes do exercício, os outros dois animais (Bovinos 5719 e5722) foram exercitados, e sempre que isso ocorria os sinais clínicos eram precipitados, acentuados e tornavam-se mais evidentes.

Início dos sintomas e evolução. O Bovino 5721 que recebeu $1 \mathrm{~g} / \mathrm{kg}$, foi encontrado morto 5 horas e 30 minutos após o início da administração da planta; a temperatura era de $38,5^{\circ} \mathrm{C}$, as mucosas estavam úmidas, não havia rigor mortis e o sangue ainda não estava coagulado. $O$ Bovino 5719 que recebeu $0,5 \mathrm{~g} / \mathrm{kg}$ apresentou os primeiros sinais clínicos 3 horas e 24 minutos após o início da administração da planta. A morte ocorreu 73 horas e 12 minutos após o aparecimento dos primeiros sinais clínicos. O Bovino 5722 , que recebeu $0,25 \mathrm{~g} / \mathrm{kg}$, apresentou os primeiros sinais clínicos 5 horas e 56 minutos após o início da administração da planta. Os sintomas duraram 28 horas e 6 minutos. Em seguida o animal se recuperou. A dose de $0,25 \mathrm{~g} / \mathrm{kg}$ não foi capaz de levar o animal a morte, porém causou sintomas.

Sintomas. O Bovino 5719 que tinha recebido a dose de $0,5 \mathrm{~g} / \mathrm{kg}$ apresentou as jugulares e veias colaterais da região da face e pescoço muito ingurgitadas, pulso venoso positivo, cabeça pendente, sonolência, taquicardia, dispnéia, mucosas levemente cianóticas, diminuição dos movimentos ruminais, algumas vezes atonia e leve timpanismo, relutância em se mover (mesmo quando tangido), tremores musculares generalizados, fezes moderadamente ressecadas, movimentos de pedalagem, decúbito e morte. Já o Bovino 5722 que recebeu a dose de $0,25 \mathrm{~g} / \mathrm{kg}$, apresentou jugulares ingurgitadas, pulso venoso positivo, taquicardia, dispnéia, tremores musculares e relutância em se mover. O animal se recuperou.

Necropsias. Bovino 5721: Havia marcado ingurgitamento das jugulares, já perceptível antes da abertura da carcaça, que estavam preenchidas por grande quantidade de sangue não-coagulado, marcada dilatação da aurícula direita e da veia cava (Fig.2) e moderada congestão hepáti-

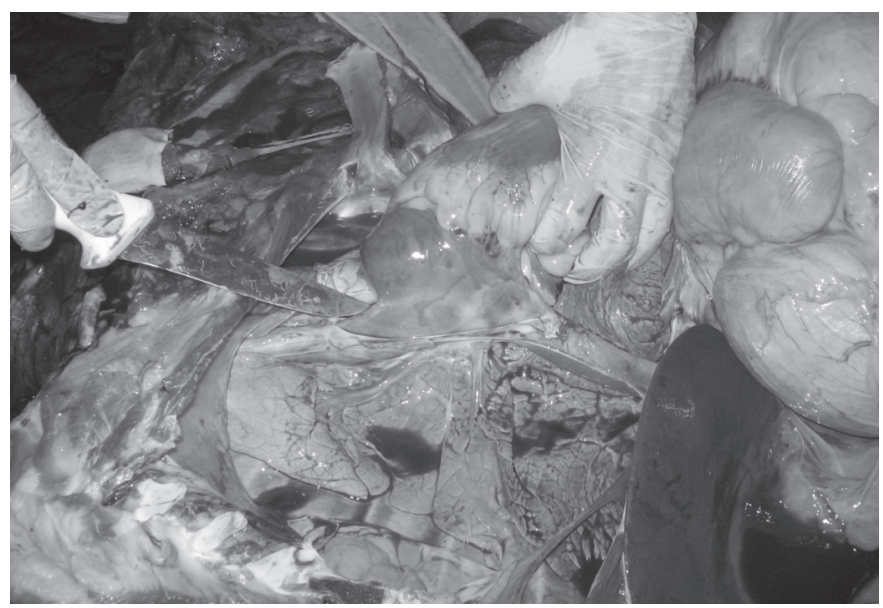

Fig.2. Morte súbita em bovinos causada pela ingestão de Pseudocalymma elegans no município de Rio Bonito, RJ. Bovino 5721 (SAP 30861). Veias cava cranial e caudal e pulmonar dilatadas e repletas de sangue. ca. O baço apresentava leve aumento de volume e a veia esplênica estava leve a moderadamente ingurgitada. Adicionalmente observou-se discreta congestão renal. - Bovino 5719: Observaram-se jugulares ingurgitadas, moderados hidrotórax e hidroperitônio, edema pulmonar, com distensão dos septos interlobulares e grande quantidade de espuma na traquéia. Havia moderada congestão hepática, da mucosa do jejuno e do abomoso (conteúdo muito ressecado). O coração estava levemente pálido, com o lado direito moderadamente dilatado. O rim apresentava-se congesto com áreas pálidas medindo 0,3-0,6cm.

Histopatologia. Bovino 5721: Observaram-se, no rim, moderada congestão, leve infiltração inflamatória intersticial linfo-plasmocitária em córtex, tumefação e vacuolização (degeneração hidrópica-vacuolar) citoplasmáticas e picnose nuclear em células epiteliais de túbulos contornados distais (Fig.3); em alguns túbulos não se observou picnose, apenas degeneração hidrópica ou estágios intermediários onde havia degeneração e picnose incipientes. No fígado havia leve a moderada vacuolização de hepatócitos, principalmente, em região centrolobular, moderada congestão em espaços-porta e em sinusóides e discreta infiltração inflamatória linfoplasmocitária portal. Não foram verificadas alterações significativas no cérebro, cerebelo, rúmen, retículo, omaso, abomaso, intestino delgado e grosso, pâncreas e baço. Bovino 5719: Não foram observadas alterações significativas no rim, apenas leve tumefação das células epiteliais dos túbulos uriníferos, no entorno das artérias arciformes. No fígado havia moderada congestão e numerosas áreas de necrose paracentral (Fig.5). Foi observada leve infiltração inflamatória mononuclear intersticial na aurícula cardíaca; no miocárdio havia alguns focos de necrose coagulativa (Fig.4), caracterizados por aumento da eosinofilia do citoplasma das fibras musculares e picnose/ cariorrexia e ou desaparecimento dos núcleos. No pulmão foi encontrada moderada a acentuada congestão e edema. Não foram verificadas alterações significativas no cérebro, cerebelo, rúmen, retículo, omaso, abomaso, intestino delgado e grosso, pâncreas e baço.

\section{Reprodução experimental em coelhos}

Coelho 1402. Sintomas e evolução: O animal estava normal e, de repente, caiu de lado, emitiu grito, fez movimentos de pedalagem, respirou profundamente algumas vezes e morreu em menos de 1 minuto, após ter começado a se debater. - Necropsia: A necropsia foi realizada logo após a morte do animal. Havia moderada congestão hepática. Dois pequenos focos avermelhados foram observados na superfície do rim direito. A mucosa uterina estava espessada e com numerosos pequenos cistos preenchidos por líquido translúcido (hiperplasia endometrial cística). No ovário observaram-se presença de corpo lúteo e de cisto paraovárico. Diversas erosões e algumas úlceras foram verificadas no estômago. Demais órgãos sem alterações. - Histopatologia: Moderada tumefação dos túbulos uriníferos, sobretudo na junção córtico-medular; 

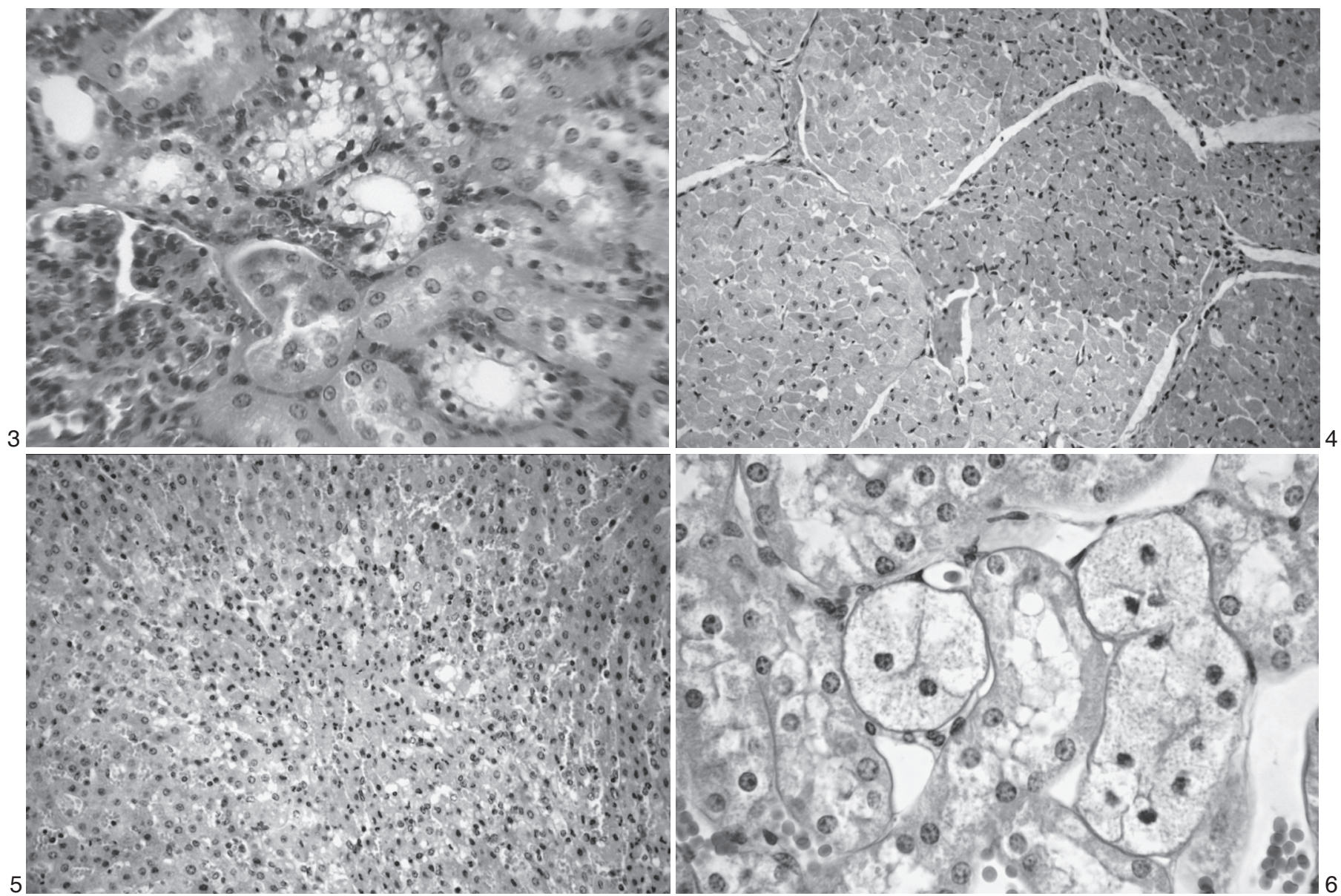

Fig.3. Morte súbita em bovinos causada pela ingestão de Pseudocalymma elegans no município de Rio Bonito, RJ. Bovino 5721 (SAP 30861). Degeneração hidrópico-vacuolar dos túbulos uriníferos contornados distais incipiente. Note a picnose nuclear. HE, obj.25x.

Fig,5. Morte súbita em bovinos causada pela ingestão de Pseudocalymma elegans no município de Rio Bonito, RJ. Bovino 5719 (SAP 30884). Necrose coagulativa paracentral. HE, obj.25x.

raros túbulos com degeneração hidrópico-vacuolar e picnose (Fig.6). O fígado apresentava acentuada congestão centro-lobular, acompanhada de leve vacuolização de hepatócitos nesta região e necrose coagulativa incipiente de hepatócitos na zona intermediária. Na bexiga foi observada acentuada tumefação difusa no urotélio. Demais órgãos sem alterações significativas.

Coelho1406. Sintomas e evolução: O animal de repente caiu de lado, esticou os membros com poucas contrações e morreu em menos de 1 minuto. - Necropsia: $O$ exame macroscópico revelou moderada congestão hepática e ingurgitação das aurículas (quase a metade do tamanho do coração) e dos grandes vasos da base do coração. Os pulmões estavam armados, com focos avermelhados, de diversos tamanhos, por vezes confluentes, distribuídos por toda superfície pulmonar; havia ainda presença de espuma, róseo-esbranquiçada nas vias aéreas

Fig.4. Morte súbita em bovinos causada pela ingestão de Pseudocalymma elegans no município de Rio Bonito, RJ. Bovino 5719 (SAP 30884). Áreas de necrose coagulativa no miocárdio.HE, obj.10x.

Fig.6. Morte súbita em bovinos causada pela ingestão de Pseudocalymma elegans no município de Rio Bonito, RJ. CoeIho 1402 (SAP 30865). Degeneração hidrópico-vacuolar dos túbulos uriníferos contornados distais. Note a picnose nuclear. HE, obj.40x.

e marcada congestão do parênquima. Os demais órgãos não apresentavam alterações significativas. - Histopatologia: No rim foi observada apenas discreta tumefação de alguns túbulos uriníferos. Na bexiga havia tumefação do urotélio. No pulmão verificaram-se áreas de congestão, edema e hemorragia. Não foram encontradas alterações nos demais órgãos.

Coelho 1413. Sintomas e evolução: O início dos sintomas ocorreu 6 horas e 59 minutos após o início da administração da planta. O coelho debateu-se bastante, emitiu gritos, apresentou contrações musculares generalizadas e grande dificuldade respiratória. A morte ocorreu em dois minutos após o início dos sintomas. - Necropsia: Havia moderada congestão hepática, com evidenciação do padrão lobular. As aurículas (quase metade do tamanho do coração) e os grandes vasos apresentavam-se bastante ingurgitados. No rim, observaram-se diversas áreas aver- 
melhadas, parte delas estava deprimida. Demais órgãos sem alterações significativas. - Histopatologia: No rim havia numerosos túbulos, sobretudo na junção córtico-medular com moderada tumefação citoplasmática; em parte deles já se observava picnose nuclear incipiente. Em alguns túbulos retos verificou-se degeneração hidrópico-vacuolar clássica bem instalada. Havia ainda moderado edema intersticial no coração, discreta congestão hepática e alguns vacúolos na sustância branca do cerebelo, além de áreas de leve enfisema pulmonar.

Dois outros coelhos que receberam $0,0625 \mathrm{~g} / \mathrm{kg} \mathrm{e}$ $0,0312 \mathrm{~g} / \mathrm{kg}$, não apresentaram quaisquer alterações.

\section{Diagnóstico}

\section{DISCUSSÃO}

O diagnóstico da intoxicação natural por Pseudocalymma elegans baseou-se na ocorrência de "morte súbita", em pelo menos um bovino (o animal estava aparentemente bem até 20 minutos antes de ter sido encontrado morto pelo proprietário) que estava em pastagem com grande quantidade dessa planta, com sinais de ter sido ingerida pelos animais, na ausência de alterações macroscópicas à necropsia e na reprodução do quadro de "morte súbita" com lesão renal microscópica característica, pela administração de exemplares de $P$. elegans coletados na pastagem onde ocorreu o surto.

Todos os casos de intoxicação ocorreram quinze a 30 dias após os animais terem sido introduzidos na área de morro da propriedade; o primeiro surto ocorreu na época da seca e o segundo, algumas semanas após o proprietário ter queimado o pasto (morro), na tentativa de combater a planta. Esses dados epidemiológicos estão de acordo com o relatado por Tokarnia et al. (2000), segundo os quais o habitat da planta é a encosta de morros, e os casos de intoxicação ocorrem na época da seca, sobretudo depois de queimadas.

Constatou-se a ocorrência do primeiro caso de "morte súbita" em bovinos causado pela $P$. elegans no município de Rio Bonito, no interior o Rio de Janeiro; só se sabia da ocorrência dessa planta no Vale do Rio Sant'Ana, município de Miguel Pereira (Mello \& Fernandes 1941) e nos municípios de Paracambi, Rio de Janeiro (Campo Grande) e Saquarema (Tokarnia et al. 2000). Trata-se do primeiro caso natural de intoxicação por $P$. elegans em bovinos cuja necropsia e exame histopatológico foram feitos, já que no único diagnóstico de intoxicação natural por $P$. elegans em bovinos, feito por Mello e Fernandes (1941), não foram descritos os achados anátomo e histopatológicos.

\section{Doses tóxicas}

Em nossos experimentos, a dose de $1 \mathrm{~g} / \mathrm{kg}$ levou o animal a morte 5 horas e 30 minutos após a ingestão da planta, tempo bem menor que o verificado por Tokarnia et al. (1969) em bovinos intoxicados com doses de 0,8 e 1,0 $\mathrm{g} / \mathrm{kg}$ da brotação da planta (12 horas e 20 minutos a 41 horas).

A menor dose capaz de causar a morte dos bovinos em nossos experimentos foi $0,5 \mathrm{~g} / \mathrm{kg}$, portanto menor que a de $0,8 \mathrm{~g} / \mathrm{kg}$ determinada por Tokarnia et al. (1969), o que demonstra que $P$. elegans da região de Rio Bonito é um pouco mais tóxica do que a colhida em Sacra Família (Miguel Pereira) e em Seropédica (Jardim de plantas tóxicas da UFRRJ), RJ. Esta planta da região de Rio Bonito pode ainda ser mais tóxica para bovinos do que $P$. marcgravii, cuja dose letal é de $0,6 \mathrm{~g} / \mathrm{kg}$ (Tokarnia et al. 2000). Mais recentemente Barbosa et al. (2003) relataram que a dose de $0,5 \mathrm{~g} / \mathrm{kg}$ de $P$. marcgravii foi capaz de causar a morte em um bovino. Em adição, em nossos experimentos a dose de $0,25 \mathrm{~g} / \mathrm{kg}$ de $P$. elegans causou 0 desenvolvimento de sintomas muito evidentes, o que não foi visto por Barbosa et al. (2003), que relataram que a dose de $0,25 \mathrm{~g} / \mathrm{kg}$ de $P$. marcgravii não determinou o aparecimento de sintomas.

Em nosso estudo experimental em coelhos, a dose de $0,125 \mathrm{~g} / \mathrm{kg}$ foi capaz de provocar a morte, portanto menor do que a dose de 0,30g/kg relatada por Tavares et al. (1974) em seus estudos com a mesma planta em coelhos. $P$. elegans da região de Rio Bonito, revelou-se tão tóxica quanto P. marcgravii para coelhos (Peixoto et al. 1987).

\section{Início dos sintomas e evolução}

O bovino intoxicado espontaneamente foi encontrado morto 20 minutos após ter sido visto sem apresentar nenhuma alteração clínica perceptível.

Nos experimentos com $P$. elegans em bovinos, os primeiros sintomas ocorreram entre 3 horas e 24 minutos $(0,5 \mathrm{~g} / \mathrm{kg})$ a 5 horas e 56 minutos $(0,25 \mathrm{~g} / \mathrm{kg})$ após a administração da planta, período portanto mais curto que 0 encontrado por Tokarnia et al. (1969) que oscilou entre 12 horas e 20 minutos e 20 horas e 40 minutos. A evolução de 73 horas e 12 minutos $(0,5 \mathrm{~g} / \mathrm{kg})$ foi bem maior que o relatado por Tokarnia et al. (1969), de poucos minutos $(1 \mathrm{~g} / \mathrm{kg})$ a 5 horas e 20 minutos $(0,8 \mathrm{~g} / \mathrm{kg})$. A evolução muito mais longa do que normalmente ocorre na grande maioria das plantas que causa "morte súbita" deve-se, provavelmente, à dose-limítrofe, ou seja, suficiente para lesar gravemente o coração e provocar insuficiência que redundou na morte do animal, mas ainda incapaz de induzir à parada cardíaca rápida, como normalmente ocorre nos casos naturais e experimentais em animais que ingerem doses maiores das plantas deste grupo.

Nos coelhos, os primeiros sintomas foram observados entre 2 horas e 52 minutos $(0,5 \mathrm{~g} / \mathrm{kg})$ e 6 horas e 59 minutos $(0,125 \mathrm{~g} / \mathrm{kg})$ após a ingestão da planta, tempo maior que o observado por Tavares et al. (1974), que foi de 1 hora e 5 minutos a 7 horas. A evolução variou entre 1 e 2 minutos.

\section{Quadro clínico-patológico}

$\mathrm{Na}$ intoxicação natural os animais apresentaram relutância em caminhar, marcha desequilibrada, queda, dificuldade para levantar, decúbito lateral, movimentos de pedalagem, tremores musculares, respiração ofegante, mugidos e morte muito rápida. Quadro similar foi descrito em experimentos realizados com $P$. elegans (Mello \& 
Fernandes 1941, Tokarnia et al. 1969, 1993, 1995, Consorte et al. 1994), bem como em experimentos feitos com outras plantas que causam "morte súbita" (Pacheco \& Carneiro 1932, Döbereiner \& Tokarnia 1959, 1982, 1983. Camargo, 1962, Tokarnia \& Döbereiner 1982, 1986, Tokania et al. 1983, 1985, 2004, Costa et al. 1984, Döbereiner et al. 1984, 1986, Peixoto et al. 1987, Barbosa et al. 2003). Alguns animais foram encontrados mortos, sem apresentar sintomas prévios, como foi o caso do animal por nós necropsiado. Esse quadro caracteriza que o animal que necropsiamos morreeu em decorrência da ingestão de $P$. elegans e não de $C$. laevigatum, que determina intoxicação com evolução de 6-48 horas (Tokarnia et al. 2000). De fato, está claro que não foi $C$. laevigatum a causa da morte desse animal, uma vez que a lesão característica (fígado de "noz-moscada", necrose centrolobular) não estava presente.

No bovino intoxicado com $1 \mathrm{~g} / \mathrm{kg}$, não foi possível acompanhar a sintomatologia, pois o animal foi encontrado morto. Nos outros dois bovinos $(0,5$ e $0,25 \mathrm{~g} / \mathrm{kg})$, a sintomatologia foi bastante uniforme: cabeça pendente, sonolência, taquicardia, ingurgitamento das veias jugulares com pulso venoso positivo, dispnéia, mucosas levemente cianóticas, diminuição dos movimentos ruminais, algumas vezes atonia e leve timpanismo, relutância em se mover (mesmo quando tangido), tremores musculares generalizados, fezes moderadamente ressecadas e decúbito seguido de movimentos de pedalagem, antes do óbito. Esses sintomas foram semelhantes aos descritos em outros experimentos com plantas do grupo das que causam "morte súbita" (Tokarnia et al. 2000). Ainda observamos marcado ingurgitamento das veias colaterais da região da face.

Os coelhos intoxicados se debatiam, caiam, apresentaram movimentos de pedalagem, dificuldade respiratória, contrações generalizadas e morte, quadro semelhante aos descritos em outros experimentos com plantas do grupo das que causam "morte súbita" (Döbereiner \& Tokarnia 1982, 1983, Tokarnia \& Döbereiner 1982, Döbereiner et al. 1984, 1986, Tokarnia et al. 1985, Peixoto et al. 1987), bem como com os relatados em cobaios e coelhos por Tavares et al. (1974).

\section{Achados de necropsia}

De todas as alterações macroscópicas descritas, as únicas já mencionadas em experimentos com $P$. elegans foram leve ressecamento do omaso (Tokarnia et al. 1969), edema pulmonar e congestão do intestino delgado (Consorte et al., 1994). Já alterações como veias jugulares e grandes vasos ingurgitados e dilatação da aurícula direita, que não foram descritas anteriormente em trabalhos com plantas que causam "morte súbita", são idênticas às observadas em animais que morrem de insuficiência cardíaca aguda (Jones et al. 2000). Essas alterações mais pronunciadas e evidentes provavelmente se deram pelo tempo de evolução, que em nossos experimentos foi mais longo do que em geral observado nos trabalhos anteriormente feitos com plantas que causam "morte súbita", com exceção de um caso de intoxicação experimental com $P$. juruana, cuja evolução se deu em 54 horas (Tokarnia et al. 1994).

Os achados de necropsia na intoxicação experimental por $P$. elegans em coelhos foram caracterizados por congestão de fígado e rim e dilatação das aurículas e grandes vasos da base do coração, alterações que também estão correlacionadas com insuficiência cardíaca.

\section{Histopatologia}

Embora no caso de intoxicação natural em bovino não tenhamos observado a típica degeneração hidrópico-vacuolar, essa lesão foi reproduzida experimentalmente em bovinos e coelhos intoxicados por $P$. elegans coletada no local onde ocorreu o surto. De qualquer forma, sabe-se que apenas parte dos bovinos intoxicados $(37,5 \%)$ por esta planta apresenta esta alteração característica no rim (Tokarnia et al. 2000), presumivelmente por morrerem de parada cardíaca antes da instalação da lesão que, acreditamos, ocorra pela eliminação do ácido monofluoracético (AM) por via renal. Por outro lado, leve infiltração inflamatória linfoplasmocitária intersticial multifocal é uma lesão comumente observada em rim de bovinos e não deve ser correlacionada à intoxicação ou à eliminação do AM, já que, sua instalação demanda mais tempo do que o período compreendido entre a ingestão da planta e o óbito. Trata-se, mais provavelmente, de uma alteração conhecida como nefrite segmentar.

Nos bovinos intoxicados experimentalmente, a maior parte das células renais que apresentava a degeneração hidrópica vacuolar, mostrava picnose nuclear, porém, em alguns túbulos não havia contração do núcleo. Acreditamos que isso apenas demonstra que parte dos túbulos ainda não havia desenvolvido a lesão clássica (degeneração hidrópico-vacuolar com picnose nuclear).

Apenas um coelho apresentou a típica degeneração hidrópico-vacuolar em túbulos contornados distais do rim, enquanto outros dois apresentaram, sobretudo na junção córtico-medular, moderada tumefação citoplasmática das células epiteliais dos túbulos (parte deles com picnose nuclear incipiente); nessas células, provavelmente, a lesão clássica ainda não estava completamente instalada. Tumefação do urotélio (verificada em dois coelhos), ainda não havia sido descrita na bexiga de quaisquer animais intoxicados natural ou experimentalmente por qualquer das plantas que causam morte súbita. Não pode ser descartada a hipótese de que essa lesão também seja secundária à presença de AM na urina.

Apesar de não sabermos se a vacuolização de hepatócitos observada na intoxicação experimental em bovino está ou não relacionada diretamente ao efeito do AM, sabe-se que ela tem sido relatada em experimentos com Pseudocalymma elegans em bovinos (Tokarnia et al. 1969), caprinos (Tokarnia et al. 1993), ovinos (Consorte et al. 1994), eqüinos (Tokarnia et al. 1995), bem como com outras plantas que causam morte súbita como Palicourea marcgravii (Peixoto et al. 1987, Tokarnia et al. 1990), P. aeneofusca (Passos 1993), P. juruana (Oliveira 
et al. 2004, Tokarnia \& Döbereiner 1982), P. grandiflora (Döbereiner \& Tokarnia 1982), Arrabidaea bilabiata (Döbereiner et al. 1984, Jabour et al. 2006, Tokarnia et al. 2004) e Mascagnia aff. rigida (Tokarnia et al. 1985). Lesão semelhante, também foi observada em hepatócitos de coelhos e cobaios intoxicados experimentalmente por $P$. elegans (Tavares et al. 1974).

Da mesma forma, necrose hepática paracentral, evidenciada em um bovino intoxicado experimentalmente, já foi observada na intoxicação experimental por $A$. bilabiata em coelhos (Jabour et al. 2006); há também referência à necrose na zona intermediária do lóbulo hepático na intoxicação experimental por $A$. bilabiata em coeIhos (Döbereiner et al. 1984). Necrose hepática incipiente na zona intermediária também foi observada em um de nossos coelhos. Todas essas lesões regressivas poderiam ser determinadas pelo próprio princípio ativo da planta ou, alternativamente, desenvolvem-se em conseqüência da estase / anóxia hepática ocasionada pela insuficiência cardíaca e choque que parecem preceder a chamada "fase dramática" da "morte súbita".

Não encontramos quaisquer referências à ocorrência de vacuolização da substância branca do SNC (cerebelo) verificada em um coelho intoxicado experimentalmente por $P$. elegans, nem temos clara a sua patogênese. Lesões semelhantes também foram evidenciadas em animais intoxicados experimentalmente por plantas que causam insuficiência cardíaca crônica, como Tetrapterys multiglandulosa (Riet-Correa et al. 2005, Tokarnia et al. 1989) e Ateleia glazioviana (Gava \& Barros 2001, Gava et al. 2001, Stigger et al. 2001, Raffi et al. 2004, 2006). No caso de intoxicação por $T$. multiglandulosa no cérebro de ovinos, a ultramicroscopia demonstrou tratar-se apenas de edema intramielínico (Riet-Correa et al. 2005).

\section{Diagnóstico diferencial}

Nenhuma outra planta do grupo das que causam "morte súbita" se desenvolve no habitat de $P$. elegans (Tokarnia et al. 2000). De qualquer forma, os pastos foram inspecionados e estas plantas não foram encontradas no local onde ocorreu a doença natural.

O carbúnculo hemático também pode provocar óbito com evolução superaguda, porém essa enfermidade, rara na região sudeste, cursa com hipertermia, aumento de linfonodos, e por vezes, sangramentos pelos orifícios naturais imediatamente após a morte, além de rápida putrefação da carcaça, "rigor mortis" ausente ou incompleto, edemas generalizados, hepatomegalia e, principalmente, marcada esplenomegalia (Langenegger 1994), achados obviamente ausentes em animais intoxicados por plantas que causam "morte súbita".

No Brasil, embora a deficiência de cobre ocorra em várias regiões, uma das manifestações de deficiência de cobre a "falling disease", só foi descrita no Rio Grande do Sul, em regiões com solos ácidos e arenosos, extremamente pobres nesse elemento, que sofrem inundações freqüentes. Nessas condições, o ferro é solubilizado e absor- vido pelas plantas, o que diminui ainda mais o conteúdo de cobre nas pastagens (Marques et al. 2003). Nos casos de "falling disease" descritos no Rio Grande do Sul, os animais não apresentaram lesões significativas na necropsia e na histopatologia, porém os autores acreditam que a autólise pode ter comprometido o exame. Já na Austrália, Bennets et al. (1948) descreveram fibrose cardíaca em bovinos com "falling disease". De qualquer forma, na propriedade em Rio Bonito, o solo não é alagado e não apresenta as características acima citadas e os animais não apresentaram hemossiderose severa, nem acromotriquia, alterações que caracterizam a deficiência de cobre.

Não é difícil fazer a diferenciação entre acidente botrópico e intoxicação por plantas que causam morte súbita, principalmente se considerarmos o inchaço local e o quadro hemorrágico que ocorre em bovinos picados por essas cobras (Caldas et al. 2008). Com relação ao acidente crotálico, não há trabalhos que relatem a ocorrência de casos naturais em bovinos no Brasil. Quase tudo que se sabe sobre a ação do veneno de serpentes desse gênero e sobre o correspondente quadro clínico-patológico do envenenamento crotálico em bovinos, se baseia na experimentação (Tokarnia \& Peixoto 2006). Animais picados por Crotalus spp. podem mostrar quadro clínico de difícil interpretação, com o agravante de, em geral, ser de rápida evolução e não cursar com lesão macroscópica visível. Esses acidentes podem mimetizar, em muitos aspectos, o quadro sintomatológico verificado em casos de botulismo ou serem confundidos com os observados em doenças que cursam com distúrbios neurológicos, sem alterações de consciência, ou mesmo com as que são determinadas por incapacitação muscular difusa. De qualquer maneira, além do quadro de paralisia flácida, a evolução é de pelo menos algumas horas, o que por si só estabelece a diferenciação (Graça et al. 2008).

Por apresentar evolução superaguda, a intoxicação por plantas cianogênicas, com freqüência, é confundida com intoxicação por plantas que causam morte súbita. Entretanto, o ácido cianídrico é absorvido rapidamente e os sintomas da intoxicação aparecem logo após ou já durante a ingestão da planta, diferentemente do que ocorre nas plantas que causam "morte súbita" (Clark \& Weiss 1952), além disso, em geral, o exame histopatológico não revela lesão significativa (Jones et al. 2000). Não havia, porém, quaisquer plantas cianogênicas no pasto onde ocorreu o surto.

\section{REFERÊNCIAS}

Barbosa J.D., Oliveira C.M.C., Tokarnia C.H. \& Riet-Correa F. 2003. Comparação da sensibilidade de bovinos e búfalos à intoxicação por Palicourea marcgravii (Rubiaceae). Pesq. Vet. Bras. 23(4):167-172.

Bennets H.W., Beck A.B. \& Harley R. 1948. The pathogenesis of "falling disease". Aust. Vet. J. 24:237-244.

Caldas S.A., Tokarnia C.H., França T.N., Brito M.F., Graça F.A.S., Coelho C.D. \& Peixoto P.V. 2008. Aspectos clínico-patológicos e laboratoriais do envenenamento experimental por Bothrops alternatus em bovinos. Pesq. Vet. Bras. 28:303-313.

Camargo W.A. 1962. Uma nova "erva-de-rato" tóxica para bovinos, Palicourea barbiflora: comparação com Palicourea marcgravii var. pubescens e Psychotria officinalis, Rubiaceae. Arqs Inst. Biológico, São Paulo, 29:1-11. 
Clark R. \& Weiss K.E. 1952. Factors contributing towards bloat in ruminants. J. South Afr. Vet. Med. Assoc. 23(2):103-106.

Consorte L.B., Peixoto P.V. \& Tokarnia C.H. 1994. Intoxicação experimental por Pseudocalymma elegans (Bignoniaceae) em ovinos. Pesq. Vet. Bras. 14(4):123-133.

Costa M.V., Nascimento E.F., Pessoa J.M. \& Costa W.R. 1984. Lesões em bovinos intoxicados por Palicourea marcgravii St. Hil. Arq. Bras. Med. Vet. Zootec. 36(5):571-580.

Couceiro J.E.M., Silva A.C.C. \& Silva J.A. 1976. Observações e ensaios sobre a alegada intoxicação de bovinos por plantas, no Estado de Pernambuco. Anais XV Congr. Bras. Med. Vet., Rio de Janeiro. (Resumo)

Döbereiner J. \& Tokarnia C.H. 1959. Intoxicação de bovinos pela "ervade-rato" (Palicourea marcgravii St. Hil.) no vale do Itapicuru, Maranhão. Arq. Inst. Biol. Anim., Rio de J., 2:83-91.

Döbereiner J. \& Tokarnia C.H. 1982. Intoxicação experimental por Palicourea grandiflora (Rubiaceae) em coelhos. Pesq. Vet. Bras. 2(3):121-124.

Döbereiner J. \& Tokarnia C.H. 1983. Intoxicação experimental por Arrabidaea japurensis (Bignoniaceae) em coelhos. Pesq. Vet. Bras. 3(3):95-97.

Döbereiner J., Rezende A.M.L. \& Tokarnia C.H. 1976. Intoxicação experimental por Baccharis coridifolia em coelhos. Pesq. Agrop. Bras. 11:27-35

Döbereiner J., Peixoto P.V. \& Tokarnia C.H. 1984. Intoxicação experimental por Arrabidaea bilabiata (Bignoniaceae) em coelhos. Pesq. Vet. Bras. 4(3):89-96.

Döbereiner J., Gava A., Consorte L.B. \& Tokarnia C.H. 1986. Intoxicação experimental por Mascagnia pubiflora (Malpighiaceae) em coeIhos. Pesq. Vet. Bras. 6(2):51-57.

Gava A., Cristani J., Branco J.V., Neves D.S., Mondadori A.J. \& Sousa R.S. 1998. Mortes súbitas em bovinos causadas pela ingestão de Mascagnia sp. (Malpighiaceae), no Estado de Santa Catarina. Pesq. Vet. Bras. 18(1):16-20.

Gava A. \& Barros C.S.L. 2001. Field observations of Ateleia glazioviana poisoning in cattle in southern Brazil. Vet. Human Toxicol. 43:37-41.

Gava A., Barros C.S.L., Pilati C., Barros S.S. \& Mori A.M. 2001. Intoxicação por Ateleia glazioviana (Leg. Papilionoideae) em bovinos. Pesq. Vet. Bras. 21:49-59.

Graca F.A.S., Peixoto P.V., Coelho C.D., Caldas S.A. \& Tokarnia C.H. 2008. Aspectos clínico-patológicos e laboratoriais do envenenamento crotálico experimental em bovinos. Pesq. Vet. Bras. 28:261-270.

Jabour F.F., Seixas J.N., Tokarnia C.H. \& Brito M.F. 2006. Variação da toxidez de Arrabidaea bilabiata (Bignoniaceae) em coelhos. Pesq. Vet. Bras. 26(3):171-176.

Jones T.C., Hunt R.D. \& King N.W. 2000. Patologia Veterinária. $6^{\underline{a}}$ ed. Manole, São Paulo.

Langenegger J. 1994. Ocorrência do carbúnculo hemático em animais no Brasil. Pesq. Vet. Bras. 4:135-136.

Marques A.P., Riet-Correa F., Soares M.P., Ortolani E.L. \& Giuliodori M.J. 2003. Mortes súbitas em bovinos associadas à carência de cobre. Pesq. Vet. Bras. 23(1):21-32.

Mello E.M.M. \& Fernandes J.S. 1941. Contribuição ao estudo de plantas tóxicas brasileiras. Serviço de Informação Agrícola, Ministério da Agricultura, Rio de Janeiro.

Oliveira C.M.C., Barbosa J.D., Macedo R.S.C., Brito M.F., Peixoto P.V. \& Tokarnia C.H. 2004. Estudo comparativo da toxidez de Palicourea juruana (Rubiaceae) para búfalos e bovinos. Pesq. Vet. Bras. 24(1):2730.

Pacheco G. \& Carneiro V. 1932. Estudos experimentais sobre plantas tóxicas. I. Intoxicação dos animais pela "erva-de-rato da mata". Revta Soc. Paulista Med. Vet. 2(2-3):23-46.

Passos D.A. 1983. Intoxicação experimental em caprinos (Capra bircus) por Palicourea aeneofusca (M. Arg.) Standl. (Rubiaceae). Disserta- ção de Mestrado, Universidade Federal Rural de Pernambuco, Recife. 40p.

Peixoto P.V., Tokarnia C.H., Döbereiner J. \& Peixoto C.S. 1987. Intoxicação experimental por Palicourea marcgravii (Rubiaceae) em coeIhos. Pesq. Vet. Bras. 7(4):117-129.

Raffi M.B., Barros R.R., Bragança J.F.M., Rech R.R., Oliveira F.N. \& Barros C.S.L. 2004. The pathogenesis of reproductive failure induced in sheep by the ingestion of Ateleia glazioviana. Vet. Hum. Toxicol. 46(5):233-238.

Raffi M.B., Rech R.R., Sallis E.S.V., Barros S.S. \& Barros C.S.L. 2006. Chronic cardiomyopathy and encephalic spongy changes in sheep experimentally fed with Ateleia glazioviana. Ciência Rural 36(6):18601866.

Riet-Correa G., Terra F.F., Schild A.L., Riet-Correa F. \& Barros S.S. 2005. Intoxicação experimental por Tetrapterys multiglandulosa (Malpighiaceae) em ovinos. Pesq. Vet. Bras. 25(2):91-96.

Stigger A.L., Barros C.S.L., Langohr I.M. \& Barros S.S. 2001. Intoxicação experimental por Ateleia glazioviana (Leg. Papilionoideae) em ovinos. Pesq. Vet. Bras. 21(3):98-108.

Tavares M.I., Rezende A.M.L. \& Döbereiner J. 1974. Intoxicação experimental por Pseudocalymma elegans em coelhos e cobaias. Pesq. Agropec. Bras. 9:91-94.

Tokarnia C.H. 2004. Comunicação pessoal (Instituto de Zootecnia, Departamento de Nutrição Animal e Pastagem, Universidade Federal Rural do Rio de Janeiro).

Tokarnia C.H. \& Döbereiner J. 1982. Intoxicação experimental por Palicourea juruana (Rubiaceae) em bovinos e coelhos. Pesq. Vet. Bras. 2(1):17-20.

Tokarnia C. H. \& Döbereiner J. 1986. Intoxicação por Palicourea marcgravii (Rubiaceae) em bovinos no Brasil. Pesq. Vet. Bras. 6(3):73-78.

Tokarnia C.H. \& Peixoto P.V. 2006. A importância dos acidentes ofídicos como causa de mortes em bovinos no Brasil. Pesq. Vet. Bras. 26(2):5568.

Tokarnia C.H., Döbereiner J., Canella C. F.C. \& Guimarães D.J. 1969. Intoxicação experimental por Pseudocalymma elegans (Vell.) Kuhlm em bovinos. Pesq. Agropec. Bras. 4:195-204.

Tokarnia C.H., Döbereiner J., Couceiro J.E.M. \& Silva A.C.C. 1983. Intoxicação por Palicourea aeneofusca (Rubiaceae), a causa de "mortes súbitas" em bovinos na Zona-da-Mata de Pernambuco. Pesq. Vet. Bras. 3(3):75-79.

Tokarnia C.H., Peixoto P.V. \& Döbereiner J. 1985. Intoxicação experimental por Mascagnia aff. rígida (Malpighiaceae) em coelhos. Pesq. Vet. Bras. 5(3):77-91.

Tokarnia C.H., Gava A., Peixoto P.V., Stolf L. \& Moraes S.S. 1989. A "doença do peito inchado" (Edema da região esternal) em bovinos no estado de Santa Catarina. Pesq. Vet. Bras. 9(3/4):73-89.

Tokarnia C.H., Peixoto P.V. \& Döbereiner J. 1990. Poisonous plants affecting heart function of cattle in Brazil. Pesq. Vet. Bras. 10(1/2):1-10.

Tokarnia C.H., Costa E.R., Barbosa J.D., Armién A.G. \& Peixoto P.V. 1993. Intoxicação experimental por Palicourea marcgravii (Rubiaceae) em eqüinos. Pesq. Vet. Bras. 13(3/4):67-72.

Tokarnia C.H., Döbereiner J. \& Peixoto P.V. 1994. Aspectos clínicopatológicos complementares das intoxicações por algumas plantas tóxicas brasileiras. Pesq. Vet. Bras. 14(4):111-122.

Tokarnia C.H., Peixoto P.V., Armién A.G., Driemeier D. \& Barbosa J.D. 1995. Intoxicação experimental por Pseudocalymma elegans (Bignoniaceae) em eqüinos. Pesq. Agropec. Bras. 15(1):35-39.

Tokarnia C.H., Döbereiner J. \& Peixoto P.V. 2000. Plantas Tóxicas do Brasil. Editora Helianthus, Rio de Janeiro.

Tokarnia C.H., Barbosa J. D., Oliveira C.M.C., Brito M.F., Oliveira R.B., Barbas L.A.L. 2004. Aspectos epidemiológicos e clínico-patológicos comparados da intoxicação por Arrabidaea bilabiata (Bignoniaceae) em búfalos e bovinos. Pesq. Vet. Bras. 24(2):74-79. 